\title{
Rancang Bangun Alat Pengukur Suhu Real Time Laboratorium Menggunakan Protokol MQTT Berbasis Internet of Things
}

\author{
Indrawata Wardhana ${ }^{(1, a) *}$, Vandri Ahmad Isnaini ${ }^{(1, b)}$, Rahmi Putri \\ Wirman $^{(1, b)}$, Rita Syafitri ${ }^{(3, d)}$ dan Akhmad Nasuha ${ }^{(2, e)}$ \\ ${ }^{(1)}$ Pusat Kajian Lingkungan Hidup, UIN Sulthan Thaha Saifuddin Jambi, Jambi, Indonesia, 36361 \\ (2) Jurusan Fisika, UIN Sulthan Thaha Saifuddin Jambi, Jambi, Indonesia, 36361 \\ ${ }^{(3)}$ Laboratorium Terpadu, UIN Sulthan Thaha Saifuddin Jambi, Jambi, Indonesia, 36361 \\ Email : ${ }^{\left({ }^{*}\right)}$ indratawaw@uinjambi.ac.id, ${ }^{(b)}$ vandri@uinjambi.ac.id, ${ }^{(c)}$ rahmi@uinjambi.ac.id, \\ ${ }^{(d)}$ ritasyafitri@uinjambi.ac.id, ${ }^{\left({ }^{e}\right)}$ nasuha@uinjambi.ac.id
}

Diterima (31 Oktober 2020), Direvisi (28 Januari 2021)

\begin{abstract}
The stable temperature in the laboratories is the major requirement for ensuring safety at work. The changes in the temperature which are oftentimes caused by precisely unrecognized factor may provide hazardous impacts on humans who are working in such place. Similar researches were conducted; however, they did not use NodeMCU as a microcontroller and MQTT protocol. This study tried to build a real-time temperature observation system using MQTT protocol based on the Internet of Things which has a fast delivery speed message. The temperature and humidity were captured by using DHT22 sensor that were then stored in database for one month. The result showed that the temperature change of the laboratory could be rapidly detected through the tests process on a certain heat-produced device. It could be analyzed periodically using the real-time application so that the impact of temperature rise could be detected quickly.
\end{abstract}

Keywords: Internet of Things (IOT), Database, MQTT, NodeMCU, DHT22 sensor

Abstrak. Suhu yang stabil di laboratorium merupakan persyaratan utama dalam menjamin keselamatan dalam bekerja. Seringkali perubahan suhu yang disebabkan banyak faktor tidak diketahui secara cepat, sehingga memiliki dampak yang membahayakan bagi manusia yang beraktifitas di laboratorium. Penelitian sejenis telah banyak dilakukan, tapi belum menggunakan NodeMCU sebagai mikrokontoller dan protokol MQTT. Penelitian ini membangun sistem pengamatan real time suhu menggunakan protokol MQTT berbasis Internet of Things yang memiliki kecepatan pengiriman yang cepat. Suhu dan kelembaban di ambil menggunakan sensor DHT22, yang kemudian disimpan dalam database selama 1 bulan. Hasil penelitian menunjukkan bahwa suhu laboratorium mampu di deteksi dengan cepat perubahannya melalui proses uji pada alat yang menghasilkan panas tertentu dan dapat dianalisa secara berkala melalui aplikasi real time sehingga dampak terkait kenaikan suhu dapat diketahui dengan cepat.

Kata kunci: Internet of Things (IOT), Database, MQTT, NodeMCU, sensor DHT22

\section{PENDAHULUAN}

Aktivitas di laboratorium bagi para peneliti fisika merupakan kegiatan rutin yang dilakukan setiap hari kerja atau hari libur. Kegiatan tersebut menghasilkan dampak fisik terutama dari peningkatan suhu ruangan akibat dari kenaikan suhu tubuh peneliti ataupun aktivitas lain seperti pembakaran dll. Kenaikan suhu ruangan 
yang tajam akibat aktivitas tersebut dapat menimbulkan dampak bagi kesehatan manusia ataupun dampak lain seperti terbakarnya bahan-bahan labor atau ruangan [1].

Berdasarkan penelitian bahwa ruangan yang baik memiliki suhu sekitar $20-23{ }^{\circ} \mathrm{C}$ , sayangnya alat pengamatan suhu yang tersedia di ruangan tidak memiliki kemampuan untuk mengamati perubahan suhu secara berkala dan tersimpan rapi didalam database. Hal ini disebabkan, penggunaan termometer analog/digital yang skalanya tertera lansung di alat pembacaan sehingga para pengguna laboratorium harus selalu mengakses perubahan suhu pada alat tersebut [1].

Penggunaan alat pengukur suhu otomatis menggunakan sensor DHT22 sangat membantu dalam menghitung suhu ruangan dalam rentang waktu tertentu, sensor ini mengukur tiap 2 detik atau $0.5 \mathrm{~Hz}$ sampling rate [2]. Sensor ini juga mampu untuk mengukur suhu ruangan dari kisaran $-40^{\circ} \mathrm{C}-80^{\circ} \mathrm{C}$ (akurasi $0.5 \%$ ) and kelembaban dari $0 \%$ sampai $100 \%$ dengan akurasi 2-5\% [2,3]. Dengan bahan kapasitor polimer, DHT22 memiliki akurasi $0.1{ }^{\circ} \mathrm{C}$ [2].

Sensor DHT22 populer dikalangan programmer disebabkan biaya murah dan dapat digunakan bersama-sama dengan mikrokontroller Arduino Uno [4] ataupun NodeMCU [5]. Selain DHT22, sensor lain yang sering digunakan yakni DHT11 [6], namun memiliki kelemahan dari akurasi.

Pada penelitian ini digunakan mikrokontroller 32-bit NodeMCU (ref) sebagai prosessor utama dalam sistem automasi. Pemilihan ini berdasarkan fakta bahwa NodeMCU lebih hemat energi [7] dan memiliki kemampuan mode tidur [8] sehingga dapat bertahan dalam jangka waktu yang lama jika menggunakan energi baterai.

Internet of things (IoT) memungkinkan layanan tingkat tinggi dengan mengkoneksikan benda fisik dan virtual yang tersedia [9] melalui koneksi internet. IoT mengkombinasikan teknologi sensor, jaringan komunikasi, dan teknologi komputer pintar untuk mencapai pemroses cerdas yang handal. Protokol jaringan yang sering digunakan pada IoT adalah MQTT. MQTT ( Massage Queuing Telemetry Transport) di desain untuk terbuka, mudah, ringan dan mudah di impelemtasikan. Kelebihan dari protokol MQTT adalah mampu menyelesaikan masalah dengan metode pushing beberapa pesan dari server ke perangkat mobile [11].

M.Bogdan dalam penelitiannya menggabungkan sensor DHT22 dengan Arduino Uno board ATMEGA328 microcontroller [4] sedangkan Wijaya menggunakan DHT11 dengan Arduino pro mini dan mengirimkan data melalui protocol HTTP port 80 yang memiliki kelemahan di besarnya data head. Kelemahan dari protokol HTTP adalah dari segi kecepatan kirim dimana mqtt memiliki kecepatan 93x lebih cepat pada jaringan 3G [12]. Findawati [7] menggunakan NodeMCU sebagai mikrokontroller dan telegram untuk menerima dan mengirimkan perintah untuk mengetaui kondisi ruangan (suhu, kebakaran dan gerak), berbeda dengan Budioko [13] menggunakan server mqtt Mosquitto untuk berkomunikasi dua arah guna mendapatkan suhu ruangan menggunakan sensor LM35, dan mengirimkan informasi melalui modul wifi esp8266. Dari beberapa penelitian tersebut tidak menggunakan database sebagai tempat menyimpan data, sehingga sulit untuk menganalisa data beberapa waktu sebelumnya.

Penelitian ini akan membangun sistem pengamatan suhu dan kelembaban menggunakan perangkat mikrokontroller NodeMCU Lua V3 (ESP-12) yang hemat energi, mengambil data melalui sensor DHT22 yang akurasinya sangat baik serta mengirimkan data melalui server MQTT 
shiftr. io dan kemudian menyimpan data tersebut dalam database Mysql. Data yang telah di proses kemudian akan disimpan di dalam database. Ada dua model penyimpanan data yang populer digunakan saat ini yakni database bersifat server stand alone ataupun database berbasiskan cloud storage [14]. Data tersebut kemudian akan di proses dan di tampilkan dalam aplikasi berbasis web. Pengiriman data dilakukan menggunakan metode QoS 0 untuk mendapatkan kecepatan maksimum dalam pengiriman [15]. Perangkat akan diuji coba pada ruangan yang terdapat perangkat pemancar gelombang elektromagnetik untuk melihat perubahan dari suhu dari alat yang mempengaruhi suhu ruangan yang menggunakan pendingin ruangan.

\section{METODE PENELITIAN}

Pada penelitian ini dilakukan perancangan desain skema, pemograman pada arduino IDE, pembuatan arsitektur monitoring suhu dan kelembaban, penyimpanan data dan diplay pada website. Untuk Bahan yang digunakan pada penelitian antara lain: mikrokontroller NodeMCU LuA V3, kabel jumper, baterai Li, kabel micro USB, LM7805, kapasitor, resistor,LED 3 warna, LCD 16x2 I2C, buzzer dan sensor suhu dan kelembaban DHT22. Desain sirkuit ditunjukkan pada Gambar 1.

Rangkaian tersebut dipindahkan ke dalam papan PCB yang telah di rangkai skemanya. NodeMCU kemudian di-install menggunakan bahasa pemograman Arduino dengan menyertakan beberapa

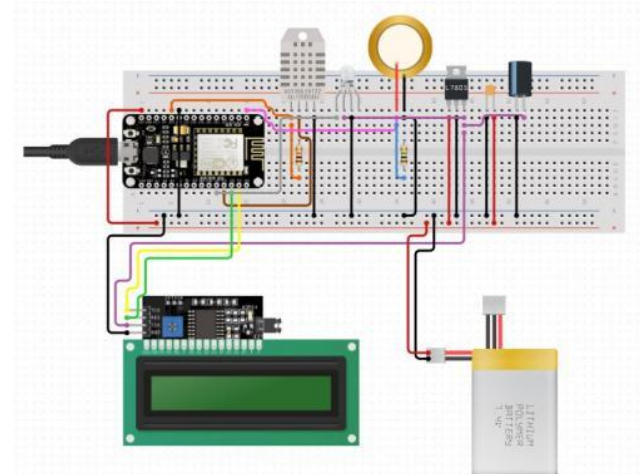

Gambar 1. Skema alat pada papan projectboard

libraries yang diperlukan: DHT library, Liquid Crystal library, Piezo library, arduino MQTT. Protokol MQTT menggunakan jaringan WiFi untuk mengirimkan data yang di cuplik per 60 detik selama 1 bulan. Pengamatan. Flowchart monitoring ditunjukkan pada Gambar 2. Data yang diterima dalam bentuk paket QoS 0 oleh mqtt broker kemudian disimpan di dalam database mysql. Data yang tersimpan didatabase masih dalam bentuk data mentah yang harus di lakukan proses pengeditan dan data cleaning jika terjadi duplikasi data atau data kosong. Dalam proses ini dilakukan dua tahapan yakni Exploratory Data Analysis (EDA) dan tampilan yang bisa diakses didalam laman website. Untuk visualisasi digunakan library python. Bahasa pemograman yang digunakan adalah PHP, CSS, Javascript, Nodejs dan HTML. 


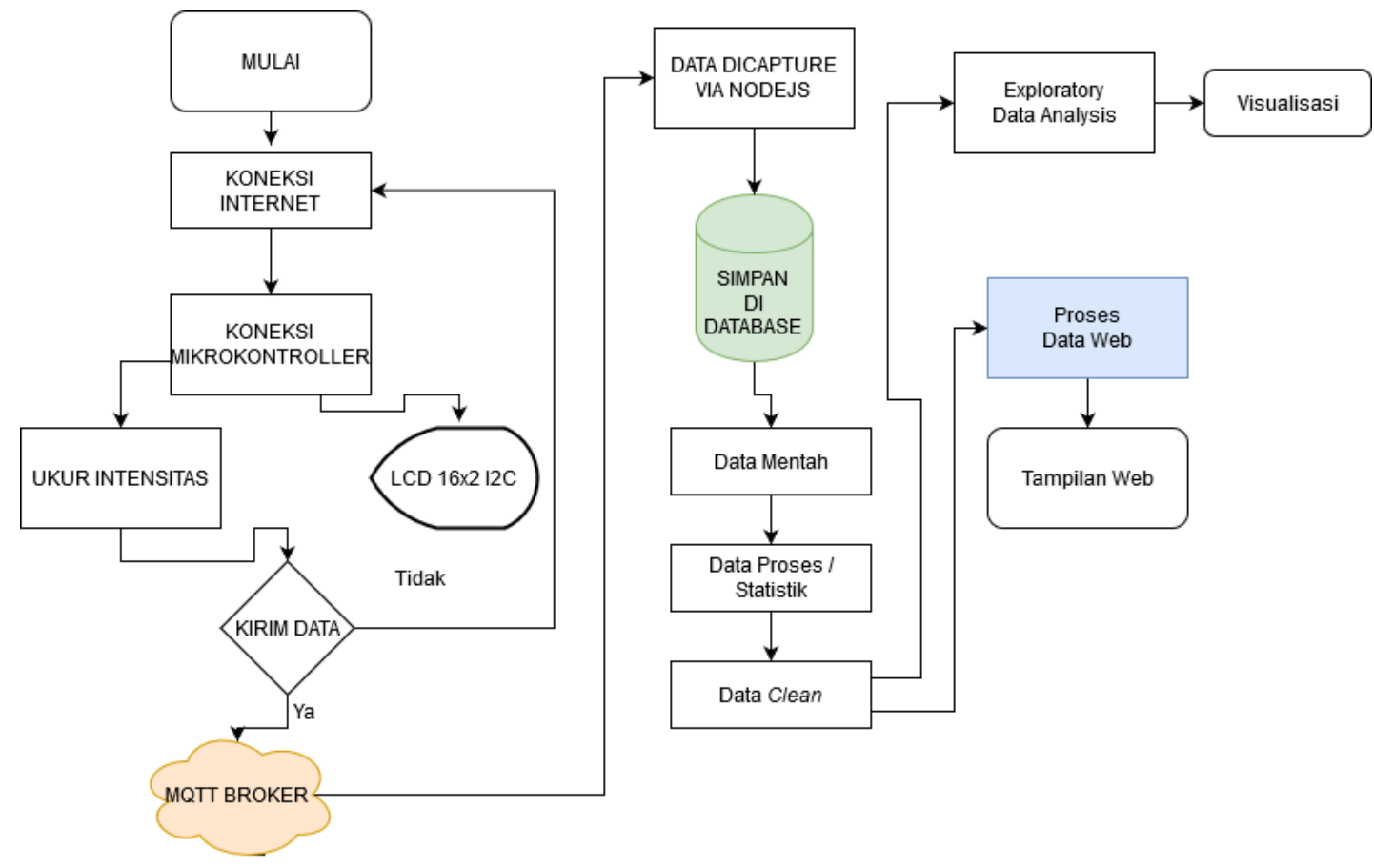

Gambar 2. Flowchart Sistem Monitoring Suhu

\section{HASIL DAN PEMBAHASAN}

\section{Pembuatan Alat}

Komponen yang telah dirancang pada papan projectboard dan telah diisi dengan pemograman arduino kemudian di pindahkan ke papan PCB sesuai desain dari skema rangkaian. Untuk menghasilkan kualitas pengukuran suhu dan kelembaban yang baik [16] , maka sensor DHT22 di letakkan pada luar kotak sisi kanan. Piezo akan akan menghasilkan bunyi saat suhu diatas $38{ }^{\circ} \mathrm{C}$. Realisasi alat ditunjukkan pada Gambar 3.

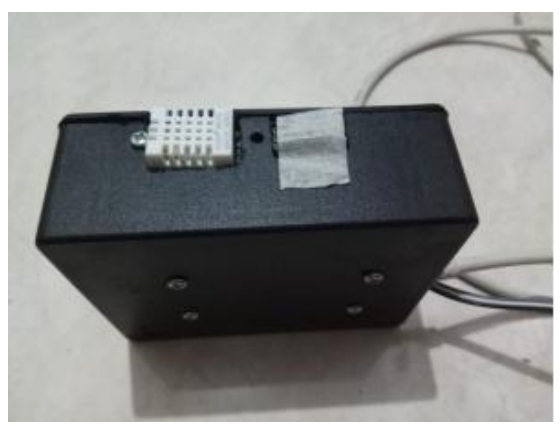

Gambar 3. Alat Pengukur Suhu Real Time
Tabel 1. Pengukuran suhu dan kelembaban DHT22

\begin{tabular}{ccc}
\hline No. & Suhu $\left({ }^{\circ} \mathrm{C}\right)$ & Kelembaban $(\%)$ \\
\hline 1 & 16.7 & 58.2 \\
2 & 16.7 & 57.7 \\
3 & 16.5 & 57.3 \\
4 & 16.4 & 57.4 \\
5 & 16.4 & 57.6 \\
\hline
\end{tabular}

Sensor yang telah dipasang kemudian di uji pada ruangan ber-AC. Pendingin diatur pada suhu $16{ }^{\circ} \mathrm{C}$, setelah 30 menit kemudian baru dilakukan pengukuran. Hasil yang didapatkan dapat dilihat pada Tabel 1. Tampak bahwa sensor mampu mendeteksi suhu dengan akurasi $0.1{ }^{\circ} \mathrm{C}$ [2] dan kelembaban $0.1 \%$.

\section{Pengujian Alat}

Untuk mendapatkan hasil yang optimal, maka dilakukan pengujian pada ruangan yang dilengkapi dengan alat yang menghasilkan panas tertentu di ruangan yang memiliki system pendingin. Pengujian dilakukan selama 24 jam tanpa henti. Dari hasil temperatur seperti yang ditunjukkan 
Gambar 4, terlihat bahwa pengukuran berlansung tanpa adanya jeda / data kosong. Terjadi fluktuasi suhu pada jam ke-6, dimana suhu minimum berada di bawah suhu $20{ }^{\circ} \mathrm{C}$. Nilai rata-rata yang terdeteksi pada kisaran $25{ }^{\circ} \mathrm{C}$. Sedangkan untuk kelembaban yang ditunjukkan pada Gambar 5, pada jam ke-12 terjadi kenaikan tajam kelembaban maksimum pada kisaran $75 \%$, di sisi lain kelembaban minimum terbesar terjadi di bawah $45 \%$ pada jam ke20. Kemudian untuk melihat seberapa cepat respon alat dalam database dilakukan pengujian yang hasilnya ditunjukkan pada Gambar 6.

\section{Data Analisis Suhu}

Pada tahap akhir, pengukuran suhu dilakukan selama 1 bulan lebih tanpa henti. Peralatan mampu bertahan dengan menggunakan sumber daya baterai selama satu bulan lebih [7] [8]. Pengujian dilakukan pada ruangan berpendingin dengan suhu diset pada $16{ }^{\circ} \mathrm{C}$ dan terdapat peralatan elektronik dalam posisi menyala dan menghasilkan panas tertentu. Dari hasil pengolahan data yang tampak pada Gambar 7, bahwa suhu rata-rata berada di kisaran $17-18{ }^{\circ} \mathrm{C}$. Angka 0-6, disimbolkan sebagai senin- minggu. Tampak bahwa pada hari minggu suhu stabil di angka 17$18{ }^{\circ} \mathrm{C}$, sedangkan pada hari kerja senin kamis, fluktuasi suhu terjadi dari $15-19{ }^{\circ} \mathrm{C}$

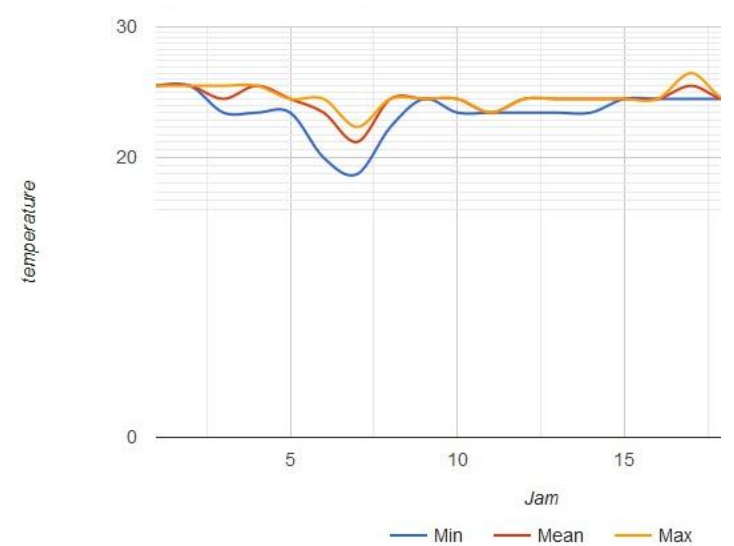

Gambar 4. Tampilan website temperatur ruangan per jam dalam 1 hari

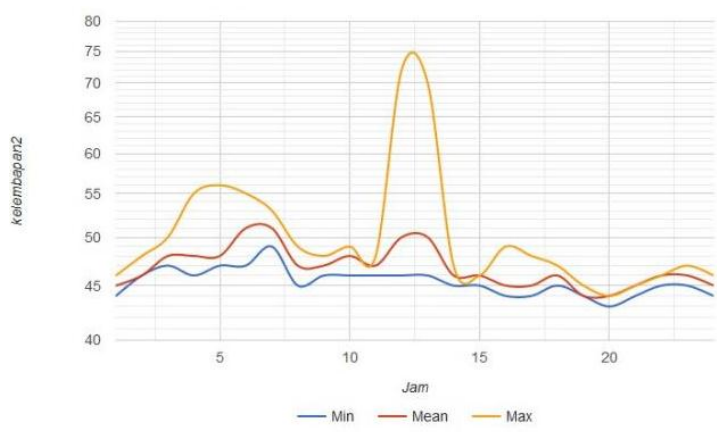

Gambar 5. Tampilan website kelembapan ruangan per jam dalam 1 hari

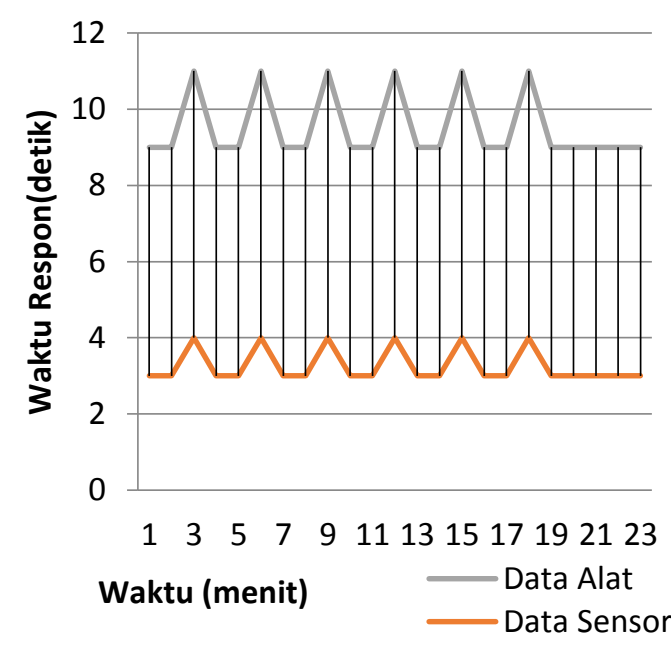

Gambar 6. Waktu respon alat pada database

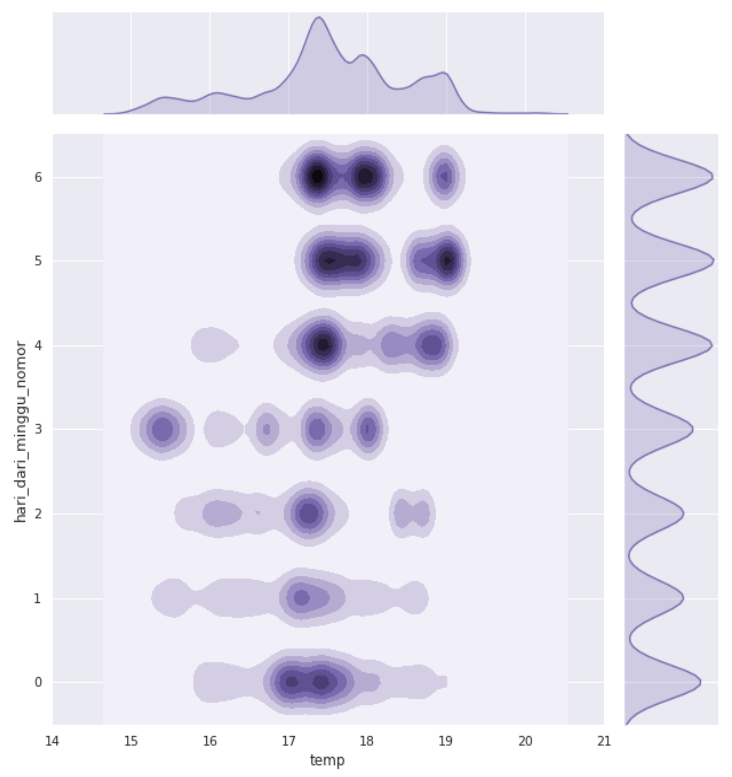

Gambar 7. Grafik joinplot suhu dengan hari mingguan 


\section{KESIMPULAN}

Berdasarkan hasil pengujian pada alat berdasarkan kondisi ruangan, peralatan yang dibangun menggunakan protokol MQTT dapat mendeteksi secara rinci perubahan suhu yang terjadi serta mampu dimonitor dalam jangka waktu yang lama. Perubahan suhu yang drastis dan cepat juga dapat di ketahui dalam hitungan detik setelah data pengukuran dikirim ke server untuk kemudian diolah kedalam tampilan website. Perbedaan waktu kirim dengan waktu terima hanya berkisar 3-4 detik. Perlu adanya kalibrasi pada laboratorium standar untuk mendapatkan suhu terkalibrasi industri.

\section{UCAPAN TERIMAKASIH}

Ucapan terima kasih kepada Laboratorium Terpadu UIN Sultan Thaha Saifuddin Jambi yang telah memberikan kemudahan akses dalam penelitian ini.

\section{DAFTAR PUSTAKA}

[1] E. Mintarto dan M. Fattahilah, "Efek Suhu Lingkungan Terhadap Fisiologi Tubuh Pada Saat Melakukan Latihan Olahraga Edy," J. Sport Exerc. Sci., vol. 2, no. 1, pp. 9-13, 2019.

[2] L. Aosong ELectronics Co, "Dht22 (Am2302)," vol. 22, pp. 1-10, 2015.

[3] A. M. Utc, "Teploměr a Vlhkoměr DHT11 a DHT22 Arduino Návody," pp. 1-16, 2019.

[4] M. Bogdan, "How to Use the DHT22 Sensor for Measuring Temperature and Humidity with the Arduino Board," ACTA Univ. Cibiniensis, vol. 68, no. 1, pp. 22-25, 2017.

[5] F. Puspasari, I. Fahrurrozi, U. Y. Oktiawati, dan T. P. Satya, "Development Of Embedded System in Monitoring Temperature and Humidity as Supporting Smart
Farm,” J. Phys. Conf. Ser., vol. 1511, no. 1, 2020.

[6] I. Vandri Ahmad Isnadi dan R. P. W. Wardhana, "Index Yang Terintegrasi dengan Pengukuran Faktor-Faktor Cuaca Secara Real Time," J. Ilm Fis., vol. 7, no. 2, pp. 63-68, 2015.

[7] Y. Findawati, A. Idris, Suprianto, Y. Rachmawati, dan E. A. Suprayitno, "IoT-Based Smart Home Controller Using NodeMCU Lua V3 Microcontroller and Telegram Chat Application," IOP Conf. Ser. Mater. Sci. Eng., vol. 874, no. 1, 2020.

[8] R. Reserved, "ESP12-F datasheet", pp. 1-2, 2018.

[9] K. K. Patel, S. M. Patel, dan P. G. Scholar, "Internet of Things-IOT: Definition, Characteristics, Architecture, Enabling Technologies, Application \& Future Challenges," Int. J. Eng. Sci. Comput., vol. 6, no. 5, pp. 1-10, 2016.

[10] J. E. Luzuriaga, M. Perez, P. Boronat, J. C. Cano, C. Calafate, and P. Manzoni, "Improving MQTT Data Delivery in Mobile Scenarios: Results from a Realistic Testbed," Mob. Inf. Syst., vol. 2016, 2016.

[11] "MQTT vs. HTTP: which one is the best for IoT? | by Marina Serozhenko | MQTT Buddy | Medium." [Online]. https://medium.com/mqttbuddy/mqtt -vs-http-which-one-is-the-best-foriot-c868169b3105. [Accessed: 04Aug-2020].

[12] T. Budioko, "Sistem Monitoring Suhu Jarak Jauh Berbasis Internet Of Things Menggunakan Protokol MQTT," Semin. Ris. Teknol. Inf. tahun, pp. 353-358, 2016.

[13] S. A. Indrawata Wardhana, "Perancangan dan Penerapan Arsitektur Cloud Storage pada IAIN STS Jambi," Manaj. Sist. Inf., vol. 2, no. 1, pp. 244-259, 2017. 
[14] M. P. Clark, "Quality of Service (QOS), Network Performance and Optimisation," in Data Networks, IP and the Internet, John Wiley \& Sons, Ltd, 2003, pp. 565-610.
[15] J. Fisika dan F. Universitas, "Kelembaban Relatif Pada Ruangan Dengan Herlina Nainggolan, Meqorry Yusfi," Kelembaban Relat., vol. 2, no. 3, pp. 140-147, 2013. 
Indrawata Wardhana: Rancang Bangun Alat Pengukur Suhu Real Time Laboratorium menggunakan Protokol MQTT Berbasis Internet of Things 